\title{
Generative Design for Additively Manufactured Textiles in Orthopaedic Applications
}

\author{
V. Ricotta ${ }^{1(凶)}$, R. Ian Campbell ${ }^{2}$, T. Ingrassia $^{1}$, and V. Nigrelli ${ }^{1}$ \\ 1 Dipartimento di Ingegneria, Università degli Studi di Palermo, Viale delle Scienze, \\ 90128 Palermo, Italy \\ vito.ricotta@unipa.it \\ ${ }^{2}$ Loughborough Design School, Loughborough University, Loughborough LE11 3TU, UK
}

\begin{abstract}
The aim of this work is to implement a new process for the design and production of orthopaedic devices to realize entirely by Additive Manufacturing (AM). In particular, a generative algorithm for parametric modelling of flexible structures to use in orthopaedic devices has been developed. The developed modelling algorithm has been applied to a case study based on the design and production of a customized elbow orthosis made by Selective Laser Sintering. The results obtained have demonstrated that the developed algorithm overcomes many drawbacks typical of traditional CAD modelling approaches. FEM simulations have been also performed to validate the design of the orthosis. The new modelling algorithm allows designers to model flexible structures with no deformations or mismatches and to create parametric CAD models to use for the production of orthopaedic devices through AM technologies.
\end{abstract}

Keywords: Additive Manufacturing - Additively manufactured textiles . Generative algorithms · CAD modelling $\cdot$ Elbow orthosis

\section{Introduction}

Additive Manufacturing (AM) is a constantly evolving technology and many researchers have explored its application in different fields, like engineering and medicine $[1,2]$. In this last field, AM has been largely used for orthopaedic applications to produce customised prostheses and orthoses [3, 4].

Customised orthoses can be better adapted to the patient's body than prefabricated devices, thus ensuring better performance $[1,2,4]$ but, usually, they could have very complex shapes. Therefore, for this kind of application, AM is the most suitable production technology because it facilitates creating complex shapes with a large variety of materials [5]. It also has lower costs than manual fabrication [6] and very good surface finish, if the process parameters are suitably chosen [7, 8].

Moreover, in recent years the use of AM has been investigated to produce flexible materials. The basic idea is to create a flexible 3D printed textile which could be used to make, for example, clothing and accessories. 
The aim of this work is to implement a new process aimed at the design and production of orthopaedic devices that are fully manufacturable by AM. For this purpose, a new modelling approach based on generative algorithms and on the use of the Additively Manufactured Textiles (AMT) technology [9] has been proposed. A test case, based on the modelling and production of a customized elbow orthosis, has been developed.

\section{AMT Flexible Structures}

To improve the aesthetics of orthopaedic devices today, thanks to modern additive technologies, it is possible to use additively manufactured textiles to create flexible structures [10] that also allow a better fit of the devices to patients.

Of course, additively manufactured textiles are very interesting and could be widely used for different applications, but the lack of efficient approaches for their 3D modelling limits their use. In this work, two different approaches have been used to model AMT structures: in the first, a standard CAD software was used; in the second, a generative algorithm $[11,12]$ was used. This second approach was developed to overcome the problems encountered during the CAD modelling of the AMT structures with conventional software.

\subsection{CAD Modelling of Flexible Structures by Commercial Software}

To investigate a standard approach to model additively manufactured textiles, a test case study related to the design and modelling of a customized elbow orthosis was developed (Fig. 1).

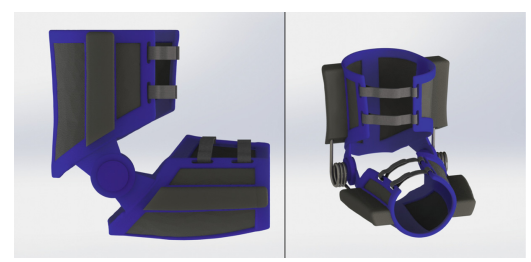

Fig. 1. CAD model of the designed elbow orthosis.

The analysed elbow prosthesis was initially modelled using a classical reverse engineering approach [13] and its structural parts were dimensioned using numerical methods [14].

The flexible structures of the orthosis were modelled using the commercial software Rhinoceros. Initially, it was decided to create flexible structures consisting of networks of rings. For this purpose, the Paneling Tools plug-in was used. The 3D basic module of the network is shown in Fig. 2 (left). The structure created and adapted to the external surface of a part of the orthosis is shown in Fig. 2 (right). 


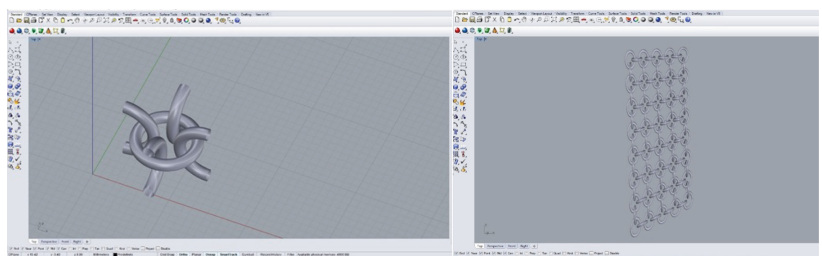

Fig. 2. Basic module to repeat (Left) - CAD model of the flexible structure by Rhinoceros (Right).

The modelling of the analysed flexible structure using this approach showed some drawbacks mainly due to the deformations of the rings of the basic module after the panelization on the surface. As shown in Fig. 3, in many cases, wide variations of the diameter of the rings were detected. In some cases, a diameter reduction of around 40-50\% was calculated. Moreover, there were also misalignments among the rings of different modules (Fig. 3).

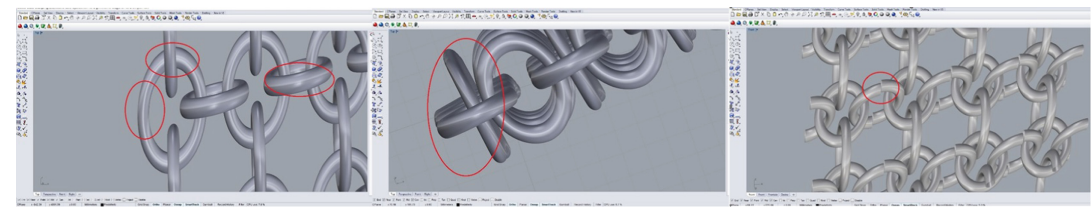

Fig. 3. Deformations and misalignments of the rings of the flexible structure using a commercial software.

The above-mentioned modelling problems, besides representing a drawback from the aesthetic point of view, could generate some problems during the manufacturing phase and could affect the strength of the structure. This aspect was confirmed during the realization of a prototype by AM. One of the two parts of the orthosis (Fig. 4), in fact, reported defects due to the deformation of the rings, while the other part was not fully made due to the too small thickness of the rings.
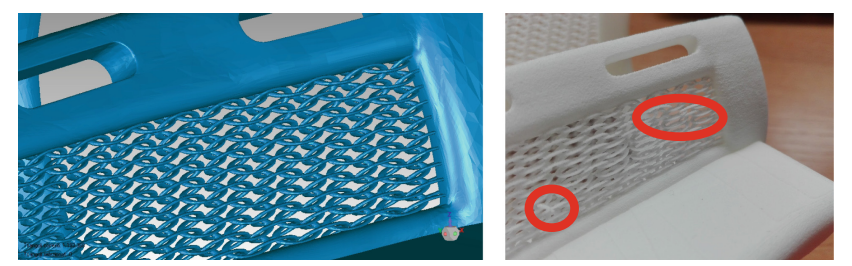

Fig. 4. STL model of flexible structure (on the left) and prototype (on the right). 


\subsection{CAD Modelling of Flexible Structures by a New Approach}

To overcome the drawbacks of the modelling of flexible structures with Rhinoceros, a new modelling approach based on generative algorithms was proposed. The new algorithm was developed using Grasshopper, a graphical algorithm editor that can be used as a plug-in to Rhinoceros. The developed algorithm allows the creation of flexible structures made of different basic modules (for example rings) that are perfectly mapped onto any surface with no deformation and/or misalignment. The algorithm consists of three main features that allow the:

- 3D parametric modelling of a basic module;

- definition of a grid of points on a surface;

- paneling of the basic module on the surface.

The function blocks diagram of the developed algorithm is shown in Fig. 5.

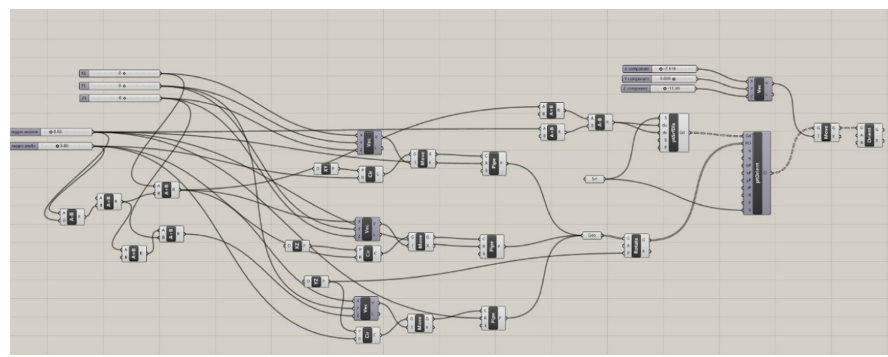

Fig. 5. Function blocks diagram in Grasshopper.

The developed algorithm was tested by modelling the same flexible structures previously created with the Rhinoceros software. Initially, the basic module was modelled. A group of three connected rings (Fig. 6) was modelled. The relative positions of the three rings were parameterized depending on the main input parameters, such as the diameters of the toroid and the transversal circular section.

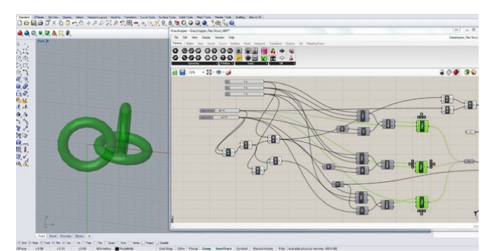

Fig. 6. Basic module (on the left) and block diagram of the 3D parametric modelling function (on the right).

The developed modelling algorithm allowed the creation of a flexible structure perfectly adapted to the surface of the orthosis (Fig. 7). 


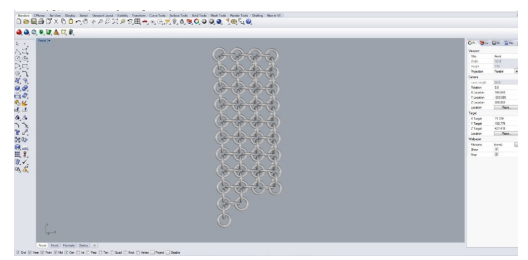

Fig. 7. Flexible structure modelled by the algorithm.

As can be seen in Fig. 8, there is no deformation, misalignment or interference among the rings.

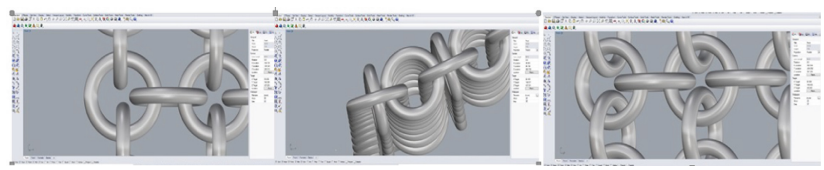

Fig. 8. Details of the flexible structure.

The final CAD model of the orthosis made through the new algorithm is shown in Fig. 9.

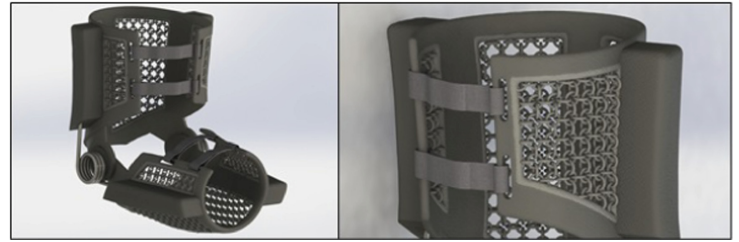

Fig. 9. CAD model of the elbow orthosis.

\section{FEM Analysis}

FEM analyses have been performed to validate the design in terms of topology and main dimensions of the structure. In fact, only the structural parts of the orthosis in PA 2200 have been analysed. In particular, the flexion and extension movements have been simulated. A very high test load, equal to $150 \mathrm{~N}$, has been imposed to the orthosis to simulate extremely hard-working conditions. Figure 10 and 11 show Von Mises stress maps during extension and flexion movements. In all cases, it can be observed that all the maximum values of the Von Mises stress are lower than the ultimate tensile stress of PA $2200(\approx 48 \mathrm{MPa})$. Experimental tests will be useful for a better characterization of the materials and validating the numerical models [15-17] in different working conditions. 


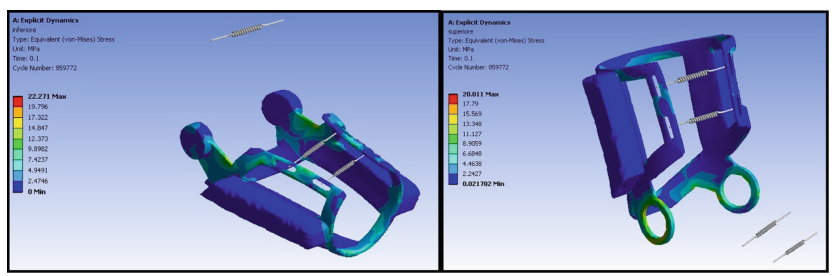

Fig. 10. Extension movement: Von Mises stress maps

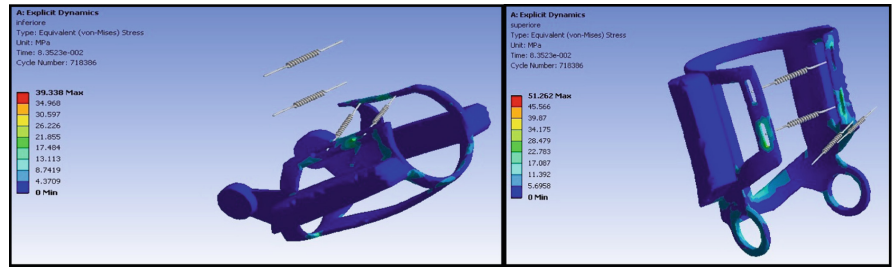

Fig. 11. Flexion movement: Von Mises stress maps

\section{Prototype Manufacturing by Additive Manufacturing}

After the CAD model of the designed orthosis was completed, a prototype of the device was produced in PA 2200 using an SLS 3D printer (EOS FORMIGA P100). PA 2200 is a fine white powder based on polyamide, used for the manufacture of products with high surface quality and very good thermal and mechanical characteristics [5]. Figure 12 shows the prototype from which it is possible to observe the good surface finish obtained with this AM technology.

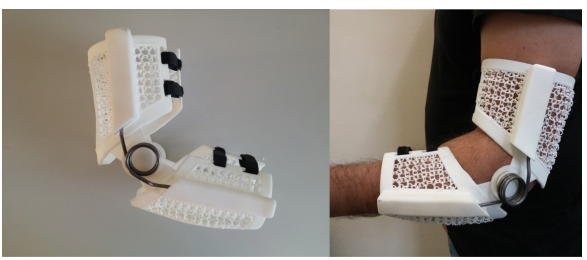

Fig. 12. Final prototype of the designed elbow orthosis.

\section{Conclusions}

In this work, a new process aimed at the design and production of orthopaedic devices fully manufacturable by Additive Manufacturing has been implemented.

To better customise and improve the aesthetic appearance of an elbow orthosis, it was decided to use Additively Manufactured Textiles technology. Initially, a commercial CAD software was used to model the non-structural parts of the orthosis and its flexible structures. This approach had some drawbacks mainly due to the deformations and 
misalignments of the AMT structures. To overcome these problems, a new modelling approach based on generative algorithms was developed. The obtained results have shown that this generative algorithm is a very good solution that allows the user to create very complex flexible structures with no drawbacks typical of traditional CAD modelling approaches. FEM analyses have been carried out considering the movements of flexion and extension of the arm. Obtained results allowed to validate the design. Subsequently, a functional prototype of the elbow orthosis has been realized by means of the SLS technology. The results present innovative elements of originality in the CAD modelling sector, which can contribute to solving problems related to modelling for Additive Manufacturing in different application fields.

\section{References}

1. Javaid, M., Haleem, A.: Additive manufacturing applications in medical cases: a review literature based. Alexandria J. Med. 54(4), 411-422 (2018)

2. Singh, S., Ramakrishna, S.: Biomedical applications of additive manufacturing: present and future. Curr. Opin. Biomed. Eng. 2, 105-115 (2017)

3. Ingrassia, T., Nalbone, L., Nigrelli, V., Ricotta, V., Pisciotta, D.: Biomechanical analysis of the humeral tray positioning in reverse shoulder arthroplasty design. Int. J. Interact. Des. Manuf. 12(2), 651-661 (2018)

4. Ingrassia, T., Nalbone, L., Nigrelli, V., Pisciotta, D., Ricotta, V.: Influence of the metaphysis positioning in a new reverse shoulder prosthesis. In: Advances on Mechanics, Design Engineering and Manufacturing, Lecture Notes in Mechanical Engineering. Springer International Publishing AG (2017). https://doi.org/10.1007/978-3-319-45781-9_47

5. Singh, S., Ramakrishna, S., Singh, R.: Material issues in additive manufacturing: a review. J. Manuf. Process. 25, 185-200 (2017)

6. Gao, W., Zhang, Y., Ramanujan, D., Ramania, K., Chen, Y., Williams, C.B., Wang, C.C.L., Shin, Y.C., Zhang, S., Zavattieri, P.D.: The status, challenges, and future of additive manufacturing in engineering. Comput. Aided Des. 69, 65-89 (2015)

7. Mancuso, A., Pitarresi, G., Saporito, A., Tumino, D.: Topological optimization of a structural naval component manufactured in FDM. In: Lecture Notes in Mechanical Engineering, pp. 451-462 (2019). https://doi.org/10.1007/978-3-030-12346-8_44

8. Ingrassia, T., Nigrelli, V., Ricotta, V., Tartamella, C.: Process parameters influence in additive manufacturing. In: Advances on Mechanics, Design Engineering and Manufacturing, Lecture Notes in Mechanical Engineering, pp. 261-270. Springer International Publishing AG (2017). https://doi.org/10.1007/978-3-319-45781-9_27

9. Lussenburg, K., Van der Velden, N., Doubrovski, Z., Geraedts, J., Karana, E.: Designing with 3D printed textiles. In: Proceedings of 5th International Conference on Additive Technologies, Wien, AT, pp. 74-81, 16-17 October 2014 (2014)

10. Bloomfield, M. and Borstrock, S.: Modeclix. The additively manufactured adaptable textile. Mater. Today Commun. 16, 212-216 (2018)

11. Krish, S.: A practical generative design method. Comput. Aided Des. 43(1), 88-100 (2011)

12. Khabazi, Z.: Generative Algorithms Using Grasshopper (2010)

13. Ricotta, V., Campbell, R.I., Ingrassia, T., Nigrelli, V.: Additively manufactured textiles and parametric modelling by generative algorithms in orthopaedic applications. Rapid Prototyping J. (2020). https://doi.org/10.1108/RPJ-05-2019-0140

14. Mancuso, A., Pitarresi, G., Tumino, D.: Using FEM simulation to predict structural performances of a sailing dinghy. Int. J. Interact. Des. Manuf. 12(3), 811-822 (2018) 
15. Tumino, D., Ingrassia, T., Nigrelli, V., Pitarresi, G., Urso Miano, V.: Mechanical behavior of a sandwich with corrugated GRP core: numerical modeling and experimental validation. Frattura ed Integrita Strutturale 30, 317-326 (2014)

16. Ingrassia, T., Lombardo, B., Nigrelli, V., Ricotta, V., Nalbone, L., D'Arienzo, A., D’Arienzo, M., Porcellini, G.: Influence of sutures configuration on the strength of tendon-patch joints for rotator cuff tears treatment. Injury 50, S18-S23 (2019)

17. Ingrassia, T., Nigrelli, V., Ricotta, V., Nalbone, L., D’Arienzo, A., D’Arienzo, M., Por cellini, G.: A new method to evaluate the influence of the glenosphere positioning on stability and range of motion of a reverse shoulder prosthesis. Injury 50, S12-S17 (2019)

Open Access This chapter is licensed under the terms of the Creative Commons Attribution 4.0 International License (http://creativecommons.org/licenses/by/4.0/), which permits use, sharing, adaptation, distribution and reproduction in any medium or format, as long as you give appropriate credit to the original author(s) and the source, provide a link to the Creative Commons license and indicate if changes were made.

The images or other third party material in this chapter are included in the chapter's Creative Commons license, unless indicated otherwise in a credit line to the material. If material is not included in the chapter's Creative Commons license and your intended use is not permitted by statutory regulation or exceeds the permitted use, you will need to obtain permission directly from the copyright holder.

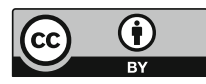

